\title{
Codependence and Conduct Disorder: Feminine Versus Masculine Coping Responses to Abusive Parenting Practices
}

\author{
Patricia V. Roehling, ${ }^{2}$ Nikole Koelbel, ${ }^{3}$ and Christina Rutgers ${ }^{4}$ \\ Hope College
}

This study supported the hypothesis that codependence reflects a stereotypically feminine coping strategy to environmental stressors, while conduct disorder represents an alternate coping response reflecting stereotypically masculine behaviors. High school students ( $\mathrm{N}=218 ; 81 \%$ Anglo-American, $8 \%$ Asian-American, 5\% Hispanic-American) completed measures of femininity/masculinity, codependence, conduct disorder, and unhealthy parenting practices. Multiple regression analyses revealed that codependence is related to parental abuse and femininity $(\mathrm{R}=.50) . A$ marginal relationship between codependence and parental alcoholism was mediated by parental abuse, calling into question the validity of the codependence construct. Conduct disorder was related to parental abuse, masculinity, parental alcoholism, and gender ( $\mathrm{R}=.62)$. The tendency to label stereotypically feminine coping strategies as pathological, while ignoring a more prevalent and destructive masculine coping strategy is discussed.

During the past fifteen years there has been a burgeoning number of books, articles and treatment programs aimed at helping the spouses and children of alcoholics. Due to the heightened levels of stress, conflict, and uncertainty that may be found in families with an alcoholic (Dinning \& Berk, 1989; Jacob, Seilhamer, \& Rushe, 1989; Jarmas \& Kazak, 1992), those fam-

\footnotetext{
${ }^{1}$ We wish to thank Mark V. Roehling, David G. Myers, John J. Shaughnessy, and Jane R. Dickie for their helpful comments and support. Portions of this research were presented at the Annual American Psychological Association Convention in Los Angeles, 1994.

${ }^{2}$ To whom correspondence should be addressed at Psychology Department, Hope College, Holland, MI 49423.

${ }^{3}$ Now at Department of Student Development, Bowling Green University.

${ }^{4}$ Now at School of Social Work, University of Michigan.
} 
ily members have an increased risk for stress related psychological and physiological problems (c.f. Sher, 1991 for a review of this literature). The most notable of these problems are conduct disorder, antisocial personality disorder, and depression.

A dominant theme among the treatment programs for family members of alcoholics is the diagnosis and treatment of codependence. Many authors believe that codependence is a form of pathology, found in family members of alcoholics, that must be treated if the afflicted individual and the alcoholic are to get well (Black, 1979; Cermak, 1991; Schaef, 1986). Although its treatment is a popular component of therapy programs, little is known about the unvalidated construct of codependence. The most serious void is that no researcher has demonstrated that codependence is more prevalent among family members of alcoholics. Nor has it been demonstrated that codependent symptoms, when present, are detrimental and therefore merit a label of pathology. Despite this lack of empirical support, thousands of individuals have been told, and continue to be told, that they require treatment for the disease of codependence. It behooves researchers to investigate this popular construct which is often unquestioningly accepted by professionals and lay people.

There is no universally agreed upon definition of codependence. All definitions of codependence, however, include a characterization of codependent individuals as over involved in recognizing and meeting the needs of others, to the exclusion of their own needs (Cermak, 1986; Morgan, 1991, Whitfield, 1989). As a result, codependents are said to place the needs of others ahead of their own and to constantly try to circumvent, both for the alcoholic and the family, the negative consequences associated with alcoholism. These caretaking behaviors are frequently called "enabling" and are considered instrumental in maintaining the alcohol abuse (Wegenscheider \& Cruse, 1989). This Responsibility/Caretaking characteristic is the codependent symptom that wives and daughters of alcoholics most frequently identify as being a problem for them (Asher \& Brissett, 1988).

These caretaking qualities bear a close resemblance to behaviors which, in Western society, are considered stereotypically feminine. The Responsibility/Caretaking characteristic is almost synonymous with the connectedness and nurturing qualities that women have been taught to embody (Tavris, 1992). Indeed, standard definitions of femininity include nurturance, interdependence, sensitivity, and emotionality (Cook, 1990), all of which are closely related to the Responsibility/Caretaking feature of codependence.

This "codependent" behavior also parallels the behaviors often identified in the subordinates in a culture (Miller, 1986). According to Miller, subordinates rely upon those who have power in society. The subordinate avoids direct and honest reactions to destructive treatment. Rather, the 
subordinate becomes highly attuned to the needs and reactions of the dominant group and concentrates upon anticipating and fulfilling those needs. In addition, the subordinate's status and feelings of self worth are directly related to the status and success of their partner. Therefore, it is in the subordinate's "best interest" to try to assist and further the success of the person who is in control, and to try to maintain that relationship. The wife or daughter of an alcoholic often is not only in a subordinate position by virtue of their gender and age, they also have relatively little economic and personal power. Therefore, their attempts to "cover" for the failures of the alcoholic and their attempts to rehabilitate the alcoholic may be a matter of survival, rather than a sign of pathology.

In any society, the dominant group is the model for "normal behavior" (Miller, 1986). Following this logic, in male dominated Western culture, stereotypically masculine behavior would be considered normal while stereotypically feminine behaviors, which deviate from the masculine standard, would be devalued and discouraged. Thus, when women respond to the stresses of living with an alcoholic by behaving in stereotypically feminine ways, such as nurturing and trying to anticipate the behavior of the alcoholic, it is considered pathological and harmful. Stereotypically masculine ways of responding to the stresses of parental alcoholism, such as conduct disordered behavior, while potentially problematic and destructive, have not been singled out for diagnosis and treatment in the way codependent behaviors have been. This is true despite ample evidence of a link between conduct disordered behavior and parental alcoholism (c.f. Johnson, Sher, \& Rolf, 1991).

Previous research has demonstrated that the constructs of codependence and femininity are related. Women have been found to score higher on measures of codependence than men (Cowan \& Warren, 1994; Fischer, Spann, \& Crawford, 1991). Also, codependence has been found to be positively associated with negatively valued feminine characteristics, and inversely related to positively valued masculine characteristics (Cowan \& Warren, 1994).

There were three goals of the present study. First, we addressed the basic question of whether parental alcoholism is related to codependence. We hypothesized that, if codependence was related to familial alcoholism, that relationship would be mediated by environmental stress, as measured by abusive parenting practices. We also hypothesized that codependence would primarily reflect femininity, and secondarily, if at all, environmental stress.

Second, we sought to replicate and extend Cowan and Warren's (1994) findings regarding the relationship between codependence and femininity. Specifically, we hypothesized that 1) women would score higher on measures of codependence and 2) codependence would be positively correlated with measures of femininity and negatively correlated with measures of masculinity. We extended the findings of Cowan and Warren in two ways. 
Our sample consists of high school rather than college students. The high school sample is more representative of the general population than the college sample, and it allows us to examine whether the relationship between codependence and femininity can be generalized to a younger population. Another way we extended the previous findings is by using two measures of codependence, both of which are different from the one used by Cowan and Warren. We were then able to determine whether the earlier results were a function of the codependence measure used by Cowan and Warren, or whether their findings reflected a true relationship.

Third, we propose that conduct disorder represents a stereotypically masculine coping response to stress. We hypothesized that, in addition to replicating the relationship between conduct disorder and parental alcoholism (c.f. Johnson, Sher, \& Rolf, 1991) and parental abuse (Pelcovitz, Kaplan, Goldenberg, \& Mandel, 1994), conduct disorder will be related to masculinity.

In order to test these hypotheses, high school students completed measures assessing codependence, conduct disorder, masculinity/femininity, parental alcoholism and abusive parenting practices.

\section{METHOD}

\section{Participants}

Participants were 218 students enrolled in a required junior-level English course at a Midwestern public high school. Fifty-five percent of the students were male. The mean age was 16.8 ranging from 16 to 18 . The majority of students were Anglo-American (81\%), $8 \%$ were Asian American, 5\% Hispanic American with fewer than 2\% belonging to other ethnic groups. Fourteen percent of the students reported that at least one of their parents were actively abusing alcohol at the time of the study. The marital status of the participants' parents were: $70 \%$ married, $20 \%$ divorced, $5 \%$ separated, $5 \%$ never married.

\section{Measures}

Codependent Questionnaire (CdQ). (Roehling \& Gaumond, 1996) The $\mathrm{CdQ}$ is a 36-item Likert scale questionnaire which assesses codependence as defined by Cermak (1986). The CdQ yields a total score and four subscale scores measuring the following dimensions: Responsibility-assuming responsibility for meeting the needs of others to the neglect of one's own needs; Control-the desire to influence and control the feelings and 
behaviors of others and oneself; Intimacy-difficulty establishing an appropriate level of intimacy with others; and Enmeshment-a tendency to become involved with personality disordered or chemically dependent individuals. The CdQ has demonstrated acceptable levels of reliability (alpha $=.86$, test-retest reliability $=.80$ ), and validity (a correlation of .53 was attained between client CdQ scores and therapists' ratings of their client's codependence) (Roehling \& Gaumond, 1996).

Fischer, Spann, \& Crawford Codependent Questionnaire (FSC). The FSC is a 16 item, 6-point Likert scale questionnaire, which was designed to assess the following three codependent characteristics: 1) an extreme focus outside of oneself, 2) a lack of open expression of feelings, and 3) attempts to derive a sense of purpose through relationships (Fischer, Spann, \& Crawford, 1991). The FSC has demonstrated an acceptable level of internal consistency (alphas ranging from .73 to .80 ) and the FSC discriminated between self-identified codependents and "recovered" codependents, demonstrating construct validity (Fischer, Spann, \& Crawford, 1991).

Extended Personal Attributes Questionnaire (EPAQ). The EPAQ is composed of 40 sets of bipolar adjectives which tap personality traits that are stereotypically gender-differentiating. (e.g. very rough vs. very gentle, not at all emotional vs. very emotional) (Helmreich, Spence, \& Wilhelm, 1981; Spence, Helmreich, \& Stapp, 1975; Spence, 1991). Participants rate, on a scale of one to five, the point between the two adjectives which they feel best describes them.

The EPAQ is not a general measure of "masculinity" and "femininity," rather it assesses specific aspects of those multi-faceted constructs (Spence, 1984). We were interested in the facets of masculinity and femininity tapped by the following five scales: 1) The masculine positive scale measures characteristically masculine attributes such as self-assertive, instrumental behaviors. 2) The feminine positive scale consists of interpersonally-oriented, expressive characteristics which are more frequently found in females than males. Attributes assessed by both the feminine positive and masculine positive scales are considered to be socially desirable in both sexes. 3) The masculine negative scale contains characteristically masculine attributes, mostly agentic in nature, which are judged to be socially undesirable in men and women. 4) The feminine negative scale reflects negatively valued feminine attributes such as communal and passive-aggressive behaviors, which are also judged to be socially undesirable in men and women. 5) The $M-F$ scale measures characteristics which are desirable for one sex but undesirable for the other. Conceptually, this scale reflects the continuum of masculinity/femininity. A high score represents a person who possesses attributes which are valued in males but not in females, while a low score represents a person who possesses attributes desirable in females but not males. 
Conduct Disorder Questionnaire. In order to derive a continuous measure of conduct disordered behavior, twenty-two behaviors, taken from the DSM-III-R (American Psychiatric Association, 1986) diagnostic criteria for conduct disorder, were identified. Participants rated on a scale of 1 to 5 (1-never, 2-once or twice in my life, 3-once a month, 4-once or twice a week, 5-daily) the frequency with which they engaged in each of the behaviors. Sample items include: physical fights, lying, stealing and injuring animals. Responses to each item are summed for a total score. The Conduct Disorder Questionnaire displayed a high level of internal consistency $($ alpha $=.89)$. The mean score for the sample was $42.17(N=202, S D=$ 11.1), ranging from 22 to 83.

Parental Alcoholism. Participants were asked the following two questions in order to assess the presence of parental alcoholism: 1) Currently, does your father or step-father have an alcohol abuse problem? 2) Currently, does your mother or step-mother have an alcohol abuse problem? Berkowitz and Perkins (1988) have found that these two items were as accurate at assessing parental alcoholism as the 30 item Children of Alcoholics Screening Test (CAST). In our sample 14\% of the subjects responded affirmatively to at least one of these questions. This is consistent with the rate of parental alcoholism reported in other studies (Berkowitz \& Perkins, 1988; Cavell, Jones, Runyan, Constantin-Page, \& Velasquez, 1993).

Abusive Parenting Practices. Participants rated, on a 5 point scale (1-rarely or never, 2-three or four times a year, 3-monthly, 4-weekly, 5-daily), the occurrence of the following behaviors during their childhood: 1) How frequently did your parents tell you that you were worthless or a failure? 2) How often did your parents yell at you? 3) How often did your parents spank you? 4) How often did your parents strike you with their fist? 5) How often did your parents leave bruises on you? 6) How often did your parents hit you with an object? (belt, stick) 7) How often did your parents confine you to a small space like a closet? A total score was calculated by summing responses to these items. The mean score for the sample was $10.9(N=211, S D=3.6)$ with scores ranging from 7 to 30 . The alpha coefficient was .76 .

\section{Procedure}

Letters describing the study were sent to the parents of potential subjects. Parents who did not want their children to participate in the study were instructed to return an attached form to their child's school denying their consent. Three forms were returned to the school. Questionnaires took approximately 25 minutes to complete and were administered during a required junior-level English course. 


\section{RESULTS}

\section{Gender Differences}

In order to explore the relationship between gender and the other independent and dependent variables used in the study, a series of t-tests were performed to compare the differences between the responses of males and females on those variables (See Table I). As hypothesized, codependence scores were higher for females, while conduct disorder scores were higher for males. Females scored significantly higher on the EPAQ scales measuring feminine attributes and males scored higher on the scales measuring masculine attributes, providing evidence that our participants' responses were consistent with gender stereotypes.

\section{Codependence}

Correlations. As we hypothesized, the findings of Cowan and Warren (1994) regarding the relationship between femininity and codependence were replicated (See Table II). Codependent scores significantly correlated with negative feminine attributes (CdQ, $r=.25$; FSC $r=.37$ ), but not with positively valued feminine attributes; and codependence correlated negatively with positive masculine attributes $(\mathrm{CdQ}, r=-.33$; FSC,

Table I. $t$-Tests Between Males and Females on the EPAQ and Measures of Codependence and Conduct Disorder

\begin{tabular}{lcccc}
\hline & $\begin{array}{c}\text { Males }^{a} \\
M(S D)\end{array}$ & $\begin{array}{c}\text { Females }^{b} \\
M(S D)\end{array}$ & $t$ & $\begin{array}{c}r \text { with } \\
\text { Gender }\end{array}$ \\
\hline CdQ total & $101(13)$ & $106(13)$ & $-2.71^{d}$ & $.19^{d}$ \\
Responsibility & $24(3.7)$ & $25(3.7)$ & $-2.03^{c}$ & $.14^{c}$ \\
Conrol & $30(4.2)$ & $31(4.4)$ & $-2.30^{c}$ & $.16^{c}$ \\
Intimacy & $28(5.4)$ & $28(5.4)$ & -.33 & .02 \\
Enmeshment & $19(3.6)$ & $21(3.7)$ & $-4.36^{d}$ & $.29^{d}$ \\
FSC & $50(11)$ & $55(12)$ & $-2.72^{d}$ & $.19^{d}$ \\
Conduct disorder & $44(12)$ & $40(9)$ & $2.49^{c}$ & $-.17^{c}$ \\
M-F & $26(4)$ & $22(5)$ & $5.66^{d}$ & $-.37^{d}$ \\
Masculinity (pos) & $31(4.6)$ & $28(5.1)$ & $3.37^{d}$ & $-.23^{d}$ \\
Masculinity (neg) & $22(4.5)$ & $20(3.9)$ & $3.07^{d}$ & $-.22^{d}$ \\
Femininity (pos) & $30(4.5)$ & $32(5.2)$ & $-2.9^{d}$ & $.20^{c}$ \\
Femininity (neg) & $20(4.3)$ & $23(3.5)$ & $-4.8^{d}$ & $.34^{d}$ \\
\hline$a_{n}=104$. & & & \\
${ }_{n} n=91$. & & & & \\
$c_{p}<.05$. & & & & \\
${ }_{p}<.01$. & & &
\end{tabular}




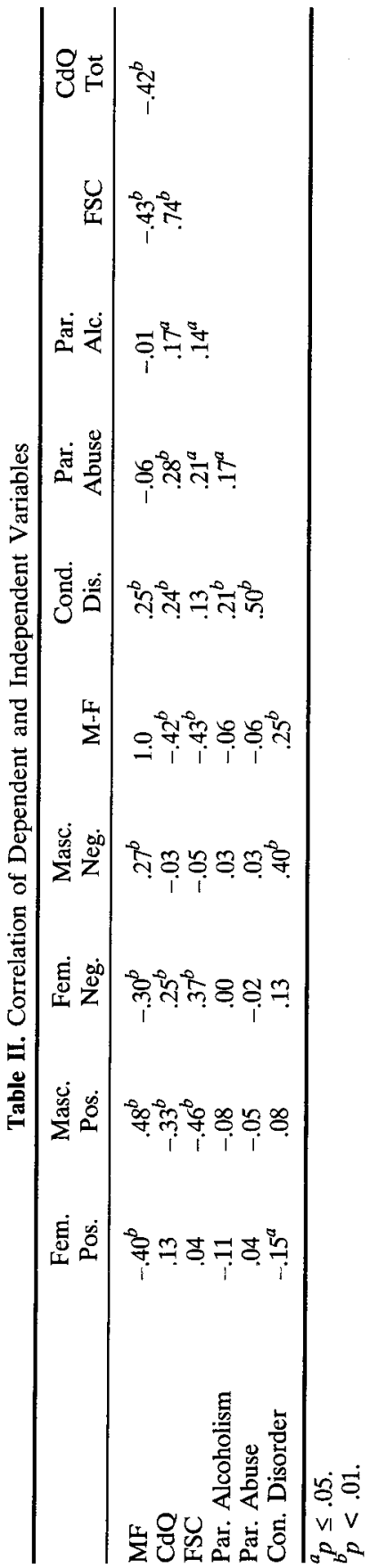


$r=-.46$ ). The M-F scale (not used by Cowan \& Warren), which measures characteristics which are differentially valued in males and females, yielded the strongest and most consistent relationship with codependence. Low M-F scores, which reflect the presence of attributes which are socially acceptable in females but not in males, were related to high levels of codependence (CdQ, $r=-.42$; FSC, $r=-.43$ ). CdQ subscale scores display a very similar pattern of results to that of the total score. Specifically, with each of the subscale scores, there was a positive correlation with negatively valued feminine characteristics, and an inverse relationship with positively valued masculine characteristics and with the M-F scale. The same pattern of results were found for both male and female participants.

These findings suggest that codependence reflects two aspects of femininity. It is related to stereotypically feminine characteristics which are negatively evaluated by our culture. Codependence also reflects feminine characteristics that are appealing in women, but are the polar opposite of culturally valued masculine attributes. Codependence does not reflect the positively valued feminine characteristics which are considered acceptable in both men and women.

Multiple Regression Analyses. The first set of regressions tests whether the relationship between codependence and parental alcohol abuse is mediated by abusive parenting practices. Three regression equations provide the test for mediation (Barron \& Kenny, 1986). First, it must be demonstrated that the predictor variable (parental alcoholism) affects the mediator variable (parental abuse). The Beta for this regression equation is $.21(p<.01)$. The second equation must demonstrate that the predictor variable (parental alcoholism) affects the criterion variable (codependence). This Beta was also significant for both the CdQ $(\beta=.17, p<$ $.05)$ and for the SF $(\beta=.14, p=.05)$. Finally, the criterion variable (codependence) must be regressed on both the predictor variable (parental alcoholism) and the mediator (parental abuse). If parental abuse mediates the relationship between parental alcoholism and codependence, then, in this third equation, parental abuse will be related to codependence and the relationship between parental alcoholism and codependence will be decreased. This was the case. When parental abuse and parental alcoholism were simultaneously entered into the regression equation the previously significant relationship between parental alcoholism and codependence was reduced and no longer significant $(\mathrm{CdQ}, \beta=.12, p=$ $.10 ; \mathrm{SF}, \beta=.11, p=.16$ ), while the relationship between parental abuse and codependence remained significant $(\mathrm{CdQ}, \beta=.25, p<.01$, SF, $\beta=$ $.18, p<.05)$. 
In order to examine the relative contributions of femininity, gender, abusive parenting practices, and parental alcoholism in understanding codependence, two hierarchical multiple regression equations were performed using the CdQ and FSC codependence scores as the criterion variables. In step 1, parental abuse, M-F, parental alcoholism, and gender were entered simultaneously. In steps 2 and 3, the two-way and then the three-way interactions were entered into the equation. The M-F score was selected for use in these analyses because it is the EPAQ scale that best reflects the continuum of masculinity-femininity and it displayed the strongest and most consistent relationship with codependence.

When the CdQ was used as the criterion variable, the predictor variables explained $25 \%$ of the variance $(R=.50, p<.01)$. Parental abuse and $\mathrm{M}-\mathrm{F}$ were significantly related to codependence, with $\mathrm{M}-\mathrm{F}$ explaining the greatest amount of the variance (See Table III). Thus, codependence is related to negatively valued feminine characteristics and to parental abuse. The two-way and three-way interactions failed to explain any additional variance (two-way: $R_{\text {change }}^{2}=.00, F=.17$; three-way: $R^{2}$ change $=.00$, $F=1.0$ ). Both boys and girls respond to parental abuse through heightened levels of codependence, regardless of their M-F scores.

A similar pattern of results was found using the FSC measure of codependence. The four predictor variables explained $22 \%$ of the variance $(R=.47)$. M-F and parental abuse were the only variables significantly related to codependence, with M-F accounting for the largest proportion of the explained variance (See Table III). The two-way and three-way interactions failed to explain any additional variance (two-way: $R_{\text {change }}^{2}=.02$, $F=1.6$, three-way: $R_{\text {change }}^{2}=.00, F=1.1$ ).

Table III. Hierarchical Multiple Regression Using Codependence Scores as the Criterion Variables $^{a}$

\begin{tabular}{lrrrl}
\hline & $\beta$ & $B$ & $t$ & $p$ \\
\hline CdQ & & & & \\
M-F & -.42 & -1.20 & -5.97 & .00 \\
Parental abuse & .24 & .87 & 3.51 & .00 \\
Gender & .01 & -.33 & -.18 & .86 \\
Parental alcohol abuse & .11 & 4.31 & 1.67 & .10 \\
FSC & & & & \\
M-F & -.40 & -1.02 & -5.48 & .00 \\
Parental abuse & .17 & .56 & 2.45 & .02 \\
Gender & .03 & .66 & .38 & .70 \\
Parental alcohol abuse & .10 & 3.30 & 1.38 & .17 \\
\hline
\end{tabular}

${ }^{a} N=174$. 


\section{Conduct Disorder}

Correlations. The hypothesis that conduct disordered behavior is associated with stereotypically masculine behavior was supported. The conduct disorder measure correlated $.40(p<.01)$ with the EPAQ negative masculinity scale and $.25(p<.01)$ with the M-F scale (See Table II). Conduct disorder was not significantly correlated with positively valued masculine traits $(r=.08)$.

Multiple Regression Analyses. In order to test the hypothesis that males rely upon aggressive, conduct disordered strategies for coping with stress, a hierarchical multiple regression analysis was performed. Conduct disorder scores served as the criterion variable. Parental alcoholism, parental abuse, $\mathrm{M}-\mathrm{F}$ and gender were entered simultaneously as the predictor variables. All four variables added significantly to the equation (See Table IV), explaining $38 \%$ of the variance $(R=.62)$. Abusive parenting practices and M-F explained the greatest amount of variance in conduct disorder scores, followed by parental alcohol abuse and gender. Thus, conduct disordered behavior is related to parental abuse, stereotypically masculine characteristics, parental alcoholism, and being male. On step 2, the two-way interactions were entered simultaneously in the regression equation. They failed to add significantly to the Multiple Regression $\left(R=.63, R_{\text {change }}=.01, p>.05\right)$.

Finally, unlike codependence, the effects of parental alcoholism on conduct disorder can not be explained by parental abuse alone. When conduct disorder is regressed on both parental alcoholism and parental abuse, the relationship between parental alcoholism and conduct disorder decreases, from $\beta=.24$ to $\beta=.14$, but is still significant, $t=2.11, p<.05$.

\section{DISCUSSION}

The present study supported the hypothesis that codependence reflects stereotypically feminine behaviors and coping strategies. Among the ado-

Table IV. Hierarchical Multiple Regression Using Conduct Disorder Scores as the Criterion Variable ${ }^{a}$

\begin{tabular}{lcccl}
\hline & $\beta$ & $B$ & $T$ & $p$ \\
\hline Parental abuse & .52 & 1.62 & 8.42 & .00 \\
M-F & .22 & .54 & 3.48 & .00 \\
Parental alcoholism & .15 & 4.94 & 2.45 & .02 \\
Gender & .13 & 2.93 & 2.01 & .04 \\
\hline
\end{tabular}

${ }^{a} N=174$. 
lescents in our sample, women scored higher than men on measures of codependence. This is consistent with the findings of other studies (Cowan \& Warren, 1994; Fisher, Spann, \& Crawford, 1991). In addition, using two separate measures of codependence, we found a strong relationship between codependence and measures of femininity among a sample of high school students. Specifically, codependence reflects negatively valued feminine characteristics, and stereotypically feminine characteristics not positively valued in men. Codependence does not reflect those characteristics considered desirable in both men and women. These findings were true for both male and female subjects. These are very reliable findings. Not only did we find almost identical results using two different measures of codependence, Cowan and Warren found the same pattern of results, using a third measure of codependence.

The present study casts serious doubt upon the claim that all family members of alcoholics will develop codependence (Cermak, 1991; Shaef, 1986). Our results revealed that, at best, there is only a tenuous relationship between parental alcoholism and codependence. Parental alcoholism attained only a small, albeit significant, correlation with our measures of codependence (.17 and .14). A stronger relationship existed between abusive parenting practices and codependence, suggesting that stresses of parental abuse result in an intensification of codependent tendencies in both men and women. When the effects for parental abuse were controlled, the relationship between parental alcoholism and codependence disappeared. Thus, the relationship existing between codependence and parental alcoholism is mediated by the abusive parenting practices sometimes associated with parental alcoholism, and not by the alcoholism, per se.

We also found support for our hypothesis that conduct disorder reflects a stereotypically masculine adaptation to unhealthy parenting practices. Conduct disorder scores were higher among the male students and they were significantly correlated with negatively valued masculine traits and also with stereotypically masculine characteristics which are not valued in women. Both parental alcoholism and abusive parenting practices were associated with heightened levels of conduct disordered behavior. There was a stronger relationship between abusive parenting practices and conduct disorder than there was between parental alcoholism and conduct disorder. However, unlike the relationship between parental alcohol abuse and codependence, the relationship between parental alcoholism and conduct disorder cannot be accounted for by abusive parenting practices alone. Parental alcoholism, even in the absence of parental abuse, is related to conduct disordered behavior, replicating earlier research (West \& Prinz, 1978). 


\section{Coping Strategies}

We propose that conduct disorder and codependence are two coping strategies, associated with opposite ends of the masculinity/femininity continuum, which are employed by adolescents facing environmental stressors such as parental abuse, and, to a lesser extent, parental alcoholism. Conduct disordered behavior reflects coping strategies associated with negatively valued masculine characteristics and with masculine characteristics which are not valued in women. Codependence reflects coping strategies associated with negatively valued feminine characteristics and with feminine characteristics which are devalued in men.

Both men and women respond to environmental stressors with heightened levels of codependence and conduct disorder. However, women display higher initial levels of codependence, while men display higher initial levels of conduct disorder. Under stressful conditions, these initial coping strategies become more pronounced and potentially problematic. Because the largest relationship existed between abusive parenting practices and both codependence and conduct disorder, we conclude that child abuse has more negative consequences for the child, resulting in a greater need for coping strategies, than parental alcoholism without concomitant abuse. These differences, however, may be due to the way the variables were measured. Parental alcoholism, being a dichotomous variable, has less variance than parental abuse, which is assessed as a continuous variable.

\section{Implications for Treatment}

The present study has three important implications for mental health professionals who work with family members of alcoholics. First, mental health professionals should stop perpetuating the myth that all family members of alcoholics will develop codependence and therefore require treatment. Based upon our study, there is not a direct relationship between parental alcoholism and codependence. Rather, codependence primarily reflects negatively valued feminine characteristics which may become exacerbated in situations of parental physical and emotional abuse.

Second, mental health professionals need to drop value-laden terms such as codependence when describing the behaviors and feelings of family members of alcoholics. The treatment community has been quick to identify stereotypically feminine responses to stress as pathological, reflecting the tendency to label behavior associated with the non-dominant group as deviant. Given the limited resources and options of many spouses and children of alcoholics, these coping responses may be the most adaptive 
available to them. Rather than labeling these feminine/codependent behaviors as pathological, they should be conceptualized as coping strategies that may or may not be adaptive in a given situation, depending upon the particulars of each person's situation and the other options available to them.

Third, mental health professionals should focus more upon the treatment of conduct disorder among children of alcoholics. There is a direct and significant relationship between parental alcoholism and conduct disorder. Conduct disordered behavior is likely to be harmful to the family member, the alcoholic, and to society. Mental health professionals and lay people have been quick to label the Responsibility/Caretaking behavior associated with codependence as pathological. At the same time, a blind eye has been turned to the pathological coping strategies associated with conduct disorder, which is associated with behavior more characteristic of the dominant group. Given the two coping strategies, conduct disorder has more obvious negative consequences for all involved. Treatment programs should place at least as much emphasis upon treating this destructive coping strategy as they have placed upon on the treatment of codependence.

\section{Future Research}

A weakness of the present study was the number of participants. Although 218 students participated in our study, only 31 (14\%) reported having at least one alcoholic parent. A larger sample of students would have increased the number of children of alcoholics in our sample, thereby raising the power of the statistics that we used. A larger sample would also have allowed for comparisons between male and female students who had alcoholic mothers versus alcoholic fathers. Children may be differentially effected by the alcohol abuse of a mother versus a father. Additionally, children may be more likely to model the coping style of the same gender parent versus the parent of the other different gender. We could not examine these relationships because of the small number of participants in each of those conditions. Future research should address these questions using a larger sample.

Although the present study answers some questions regarding the nature of codependence, researchers need to examine the relationship between codependent/feminine coping styles and the long term mental health of both the alcoholic and the individual employing the coping strategy. To date, theorists have assumed, without empirical validation, that codependent coping strategies are harmful, both to the codependent individual and to the alcoholic. A further examination of the impact of these coping strate- 
gies on both the alcoholic and the family members of the alcoholic is warranted.

\section{REFERENCES}

Asher, R., \& Brissett, D. (1988). Codependency: A view from women married to alcoholics. The International Journal of the Addictions, 23, 331-350.

American Psychiatric Association. (1987). Diagnostic and statistical manual of mental disorders. (3rd ed., rev.). Washington, DC: Author.

Baron, R. M., \& Kenny, D. A. (1986). The moderator-mediator variable distinction in social psychological research: Conceptual, strategic, and statistical considerations. Journal of Personality and Social Psychology, 51, 1173-1182.

Berkowitz, A., \& Perkins, H. W. (1988). Personality characteristics of children of alcoholics. Journal of Consulting and Clinical Psychology, 56, 206-209.

Black, C. (1979). Children of alcoholics. Alcohol Health and Research World, 4, 23-27.

Cavell, T. A., Jones, D. C., Runyan, R. D., Constantin-Page, L. P., \& Velasquez, J. M. (1993). Perceptions of attachment and the adjustment of adolescents with alcoholic fathers. Journal of Family Psychology, 7, 204-212.

Cermak, T. L. (1986). Diagnosing and treating co-dependence: $A$ guide for professionals who work with chemical dependents, their spouses and children. Minneapolis, MN: Johnson Institute Books.

Cermak, T. L. (1991). Co-addiction as a disease. Psychiatric Annals, 21, 266-272.

Cook, E. P. (1990). Gender and psychological distress. Journal of Counseling and Development, $68,371-375$.

Cowan, G., \& Warren, L. W. (1994). Codependency and gender-stereotyped traits. Sex Roles, $30,631-645$.

Dinning, W. D., \& Berk, L. A. (1989). The children of alcoholics screening test: Relationship to sex, family environment, and social adjustment in adolescents. Journal of Clinical Psychology, 45, 335-339.

Fischer, J. L., Spann, L., \& Crawford, D. (1991). Measuring codependency. Alcoholism Treatment Quarterly, 8, 87-99.

Helmreich, R. L., Spence, J. T., \& Wilhelm, J. A. (1981). A psychometric analysis of the Personal Attributes Questionnaire. Sex Roles, 7, 1097-1109.

Jarmas, A. L., \& Kazak, A. E. (1992). Young adult children of alcoholic fathers: Depressive experiences, coping styles and family systems. Journal of Consulting and Clinical Psychology, 60, 244-251.

Jacob, T., Seilhamer, R., \& Rushe, R. H. (1989). Alcoholism and family interaction: An experimental paradigm. American Journal or Drug and Alcohol Abuse, 15, 73-91.

Johnson, J. L., Sher, K. J., \& Rolf, J. E. (1991). Models of vulnerability to psychopathology in children of alcoholics. Alcohol Health and Research World, 15, 33-42.

Martin, E. D., \& Sher, K. J. (1994). Family history of alcoholism, alcohol use disorders and the five-factor model of personality. Journal of Studies on Alcohol, 55, 81-90.

Miller, J. B. (1986). Toward a new psychology of women (2nd ed.) Boston: Beacon.

Morgan, J. P. (1991). What is codependency? Journal of Clinical Psychology, 47, 720-729.

Pelcovitz, D., Kaplan, S., Goldenberg, B., \& Mandel, F. (1994). Post-traumatic stress disorder in physically abused adolescents. Journal of the American Academy of Child and Adolescent Psychiatry, 33, 305-312.

Roehling, P. V., \& Gaumond, E. (1996). Reliability and validity of the codependent questionnaire. Alcoholism Treatment Quarterly, 14, 85-95.

Schaef, A. W. (1986). Co-dependence: Misunderstood-mistreated. San Francisco: Harper \& Row.

Sher, K. J. (1991). Children of alcoholics: A critical appraisal of theory and research. Chicago: University of Chicago Press. 
Spence, J. T. (1984). Masculinity, femininity, and gender-related traits: A conceptual analysis and critique of current research. In B. A. Maher (Ed.), Progress in experimental research. New York: Academic Press.

Spence, J. T. (1991). Do the BSRI and PAQ measure the same or different concepts? Psychology of Women Quarterly, 15, 141-165.

Spence, J. T., Helmreich, R. L., \& Stapp, J. (1975). Ratings of self and peers on sex-role attributes and their relations to self-esteem and conceptions of masculinity and femininity. Journal of Personality and Social Psychology, 32, 29-39.

Tavris, C. (1992). The mismeasure of woman. New York: Simon \& Schuster.

Wegenscheider-Cruse, S. (1989). Another chance: Hope and health for the alcoholic family (2nd ed.). Palo Alto, CA: Science and Behavior Books.

West, M. O., \& Prinz, R. J. (1987). Parental alcoholism and childhood psychopathology. Psychological Bulletin, 102, 204-218.

Whitfield, C. L. (1989). Co-dependence: Our most common addiction-some physical, mental, emotional and spiritual perspectives. Alcoholism Treatment Quarterly, 6, 19-36. 